\title{
Triangle Method for Estimating Soil Surface Wetness from Satellite Imagery in Allahabad District, Uttar Pradesh, India
}

\author{
Abba Aliyu Kasim, Abubakar Aminu Usman \\ Department of Soil Water, Land Engineering \& Management, Sam Higginbottom Institute of Agriculture, \\ Technology \& Sciences, Allahabad, India \\ Email: abbaaliyukasim@yahoo.com
}

Received 2 December 2015; accepted 10 January 2016; published 13 January 2016

Copyright (C) 2016 by authors and Scientific Research Publishing Inc.

This work is licensed under the Creative Commons Attribution International License (CC BY). http://creativecommons.org/licenses/by/4.0/

c) (i) Open Access

\begin{abstract}
Soil surface wetness is indispensable land surface parameter in agriculture, hydrology and environmental engineering. This paper explores the relationship between surface radiant temperature and fractional vegetation cover derived from satellite imagery to estimate soil surface wetness (triangle method) in Allahabad district. The pixel distributions create triangular shapes because the range of surface radiant temperature decreases as the amount of vegetation cover increases and sufficient number of pixels exists. A very weak correlation is found between the simulated soil surface wetness and ground measured soil moisture at deeper soil layers $\left(R^{2}<0.15\right)$ on all the dates under investigation. This is because the drying rates at the surface discontinue to be linearly correlated to that at lower levels (depths). The standing water pixels distort the shape of the triangle especially at lower left edge of the triangle. This distortion is removable. The spatial and temporal inhomogeneity of soil surface wetness is examined.
\end{abstract}

\section{Keywords}

Triangle Method, Soil Surface Wetness, Surface Radiant Temperature, Fractional Vegetation Cover

\section{Introduction}

The demand for spatially distributed land surface information such as soil surface wetness in agriculture, hydrology and environmental engineering is now increasing exponentially than before [1]. Soil surface wetness influences the interactions between the land surface and atmospheric processes such as partitioning of energy into sensible and latent heat fluxes [2].

How to cite this paper: Kasim, A.A. and Usman, A.A. (2016) Triangle Method for Estimating Soil Surface Wetness from Satellite Imagery in Allahabad District, Uttar Pradesh, India. Journal of Geoscience and Environment Protection, 4, 84-92. 
Soil moisture is highly variable in space and time; therefore point based measurements are difficult, cumbersome to obtain over wide area [3]. Remote sensing as geospatial technology has excellent capabilities to infer moisture availability (soil surface wetness) over a target at a specific time. Therefore, soil surface wetness can be mapped so as to give adequate information for certain users in agriculture and hydrology [4].

The retrieval of soil moisture from satellite measurements has been the special interest for many researchers from 1978 hitherto (the launching date of SAR system with Seasat). Microwave portion of the electromagnetic spectrum is first proved to be successful for retrieval of soil moisture and vegetation parameters [1]. Other techniques such as Optical/TIR (triangle method), thermal inertia, gamma radiation and hyperspectral have been proposed and successfully carried out for inferring soil surface wetness from satellite data [3] [5].

The Triangle Method for estimating land surface moisture and energy fluxes emerged in 1990's [6]. The method uses the relationship between scaled surface radiant temperature and fractional vegetation cover derived from remotely sensed data. The underlying principle of this method is that surface radiant temperature is sensitively dependent upon soil surface wetness. Hence, spatial and temporal variations in surface wetness are reflected by variations in surface radiant temperature.

The merits of remote sensing techniques for monitoring surface soil moisture over the traditional means include: synoptic, timely coverage with good repeat passes (temporal resolution) and efficiencies of scales [7]. Specifically, the great importance of the triangle method is that it does not need ancillary atmospheric and surface data [6]. This paper is aimed at using the Triangle Method to estimate soil surface wetness in Allahabad district of Uttar Pradesh, India.

\section{Materials and Methodology}

\subsection{Materials}

\subsubsection{Study Area}

This study was conducted in Allahabad district. Allahabad district is enclosed between latitude $25.45^{\circ} \mathrm{N}$ and longitude $81.84^{\circ}$ at an elevation of 98 meters (322 ft) above mean sea level [8]. The district is situated in the southern part of the Uttar Pradesh, India. Six (6) Tehsils (geographical areas) were chosen for the study. These are Karchhana, Phulpur, Bara, Koraon, Soraon and Handia (Figure 1). Chaka Block (sub-study area) which is situated within the Karchhana Tehsil was selected as soil sampling site (Figure 1).

The typical climate of Allahabad is humid subtropical climate denoted as Cwa in the Köppen climate classification. This type of climate is common to cities in north-central India. The annual rain is about $1027 \mathrm{~mm}$. The temperature ranges from $40^{\circ} \mathrm{C}$ to $45^{\circ} \mathrm{C}$ and from $2^{\circ} \mathrm{C}$ to $24^{\circ} \mathrm{C}$ during summer and winter respectively [8] [9].

The soils of Allahabad district were developed under the synergistic impacts of a wide range of soil forming factors including climate, vegetation and parent materials. The area is covered by layers of alluvium spread by the slow-moving rivers of the Ganges system [10]. Alluvial soils are the most fertile soils among all Indian soils
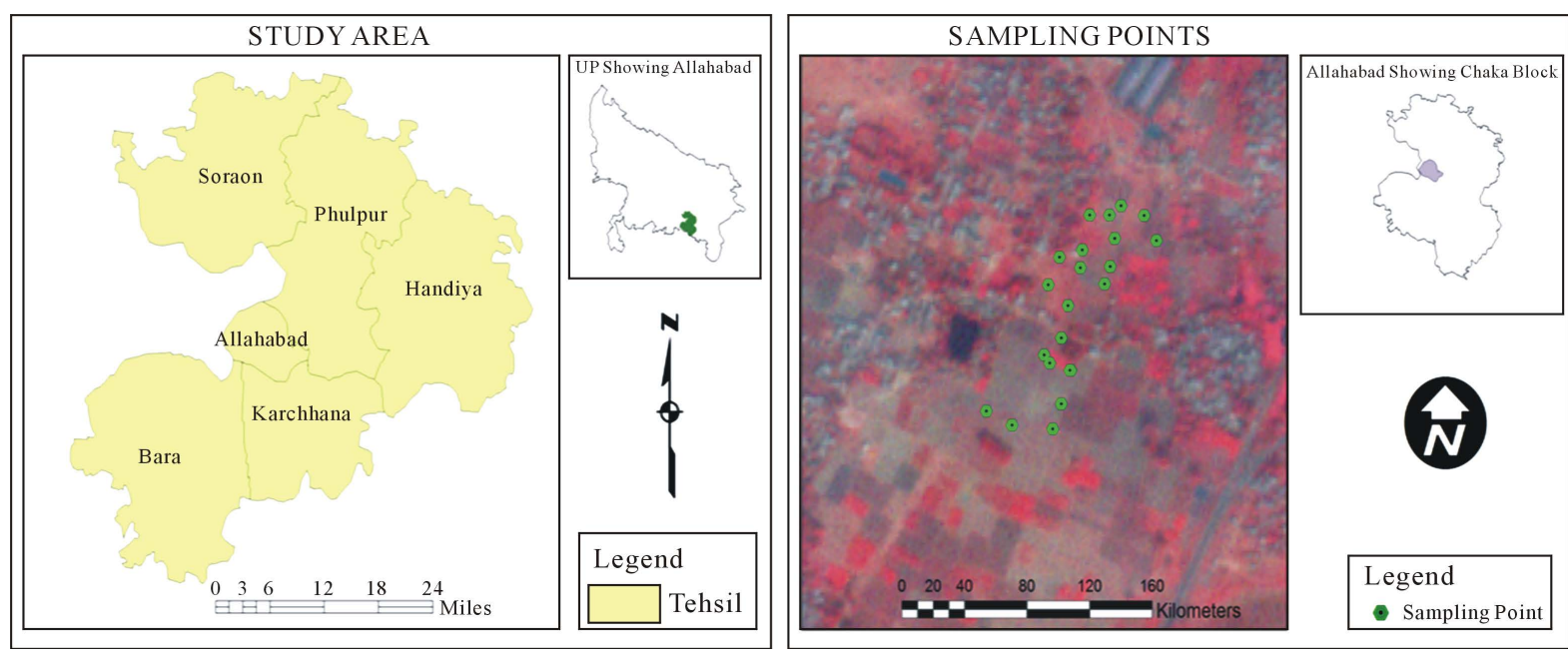

Figure 1. Study area and sampling points. 
[11]. Chaka block has moderately shallow and eroded loamy soils [12]. The vegetation of the study site consists mainly of scrub. Forests lie in Trans-Yamuna and some portions of the Vindhya Hills.

\subsubsection{Dataset Description}

This study made use of Landsat 7 Enhanced Thematic Mapper Plus data. The ETM+ sensor onboard Landsat 7 image consists of 8 spectral bands (blue, green, red, near-infrared, shortwave infrared, thermal infrared and panchromatic).

Landsat 7 ETM+ data (Path/Row 143/42) was procured from United States Geological Survey (USGS) site (http://glovis.usgs.gov). The acquisition dates of the images are 30 $0^{\text {th }}$ January, 2015; 15th February, 2015; 19th March, 2015; 20th April, 2015 and 6th May, 2015. The images of 3rd March, 2015 and 4th April were very cloudy.

\subsubsection{In Situ Measurements}

Soil samples were collected at some locations (22 sampling points) in Chaka Development Block area at two depths $(0-5 \mathrm{~cm}$ and $5-15 \mathrm{~cm})$. The Landsat $7 \mathrm{ETM}+$ overpass time is 5:00 am GMT which corresponds to 10:30 am Indian time. Therefore, soil sampling was carried out between 10:30 and 11:30 am (local time of India). Gravimetric method was used to determine the moisture content using procedures explained in [11].

\subsection{Methodology}

\subsubsection{Data Pre-Processing}

The brightness values (DNs) were converted to radiance $\left(\mathrm{W} \mathrm{m}^{-2} \mathrm{sr}^{-1} \mu \mathrm{m}^{-1}\right.$ ) using the radiometric calibration coefficients of Landsat 7 ETM+ according to [13] procedure.

$$
L_{\lambda}=G_{\text {rescale }} \times Q_{\text {cal }}+B_{\text {rescale }}
$$

where:

$$
\begin{gathered}
G_{\text {rescale }}=\frac{\operatorname{LMAX}_{\lambda}-\operatorname{LMIN}_{\lambda}}{Q_{\text {calmax }}-Q_{\text {calmin }}} \\
B_{\text {rescale }}=\operatorname{LMIN}_{\lambda}-\left(\frac{\operatorname{LMAX}_{\lambda}-\operatorname{LMIN}_{\lambda}}{Q_{\text {calmax }}-Q_{\text {calmin }}}\right)\left(Q_{\text {calmin }}\right)
\end{gathered}
$$

$L_{\lambda}=$ Spectral radiance at the sensor's aperture $\left[\mathrm{W} /\left(\mathrm{m}^{2} \mathrm{sr} \mu \mathrm{m}\right)\right] ; Q_{\text {cal }}=$ Quantized calibrated pixel value [DN]; $G_{\text {rescale }}=$ Band-specific rescaling gain factor $\left[\left(\mathrm{W} /\left(\mathrm{m}^{2} \mathrm{sr} \mu \mathrm{m}\right)\right) / \mathrm{DN}\right] ; B_{\text {rescale }}=$ Band-specific rescaling bias factor $\left[\mathrm{W} /\left(\mathrm{m}^{2} \mathrm{sr} \mu \mathrm{m}\right)\right]$.

The at-satellite band reflectance (BD) was computed from at satellite directional radiance as follows: [13] [14].

$$
\rho_{t, b}=\frac{\pi \cdot L_{t, b} \cdot d^{2}}{\mathrm{ESUN}_{b} \cdot \cos \theta r e l}
$$

where: $\rho_{t, b}$ is at-satellite band reflectance (BD)/Planetary TOA reflectance [unitless]; $\pi$ is mathematical constant equal to $\sim 3.14159$ [unitless]; $L_{t, b}$ is at-satellite spectral radiance in band $b\left(\mathrm{~W} \mathrm{~m}^{-2} \mathrm{sr}^{-1} \mu \mathrm{m}^{-1}\right)$; $\mathrm{ESUN}_{b}$ is the mean solar exoatmospheric radiation over band $b\left(\mathrm{~W} \mathrm{~m}^{-2} \mathrm{sr}^{-1} \mu \mathrm{m}^{-1}\right)$; $\theta$ rel is solar incident angle or solar zenith angle relative to the land surface slope and $d^{2}$ is earth-sun distance in astronomical unit. The parameter $d^{2}$ is computed as the function of day of year using the following equation: [13] [14].

$$
d^{2}=\frac{1}{1+0.033 \cos (D O Y .2 \pi / 365)}
$$

where DOY is day of year and (DOY.2 $\pi / 365)$ (rad).

\subsubsection{Derivation of Normalized Difference Vegetation Index (NDVI) and Fractional Vegetation Cover}

NDVI which is a function of the surface derived reflectance in the Red and NIR bands was calculated using the 
following formula:

$$
\mathrm{NDVI}=\frac{\rho_{\text {nir }}-\rho_{\text {red }}}{\rho_{\text {nir }}+\rho_{\text {red }}}
$$

where: $\rho_{\text {nir }}$ is reflectance in the near-infrared band; $\rho_{\text {red }}$ is reflectance in the red band.

Fractional vegetation cover was derived from the scaled NDVI $\left(N^{*}\right)$.

$$
\mathrm{Fr}=\mathrm{N}^{* 2}
$$

where $N^{*}$ is calculated using the following formula as:

$$
N^{*}=\frac{\mathrm{NDVI}-\mathrm{NDVI}_{0}}{\mathrm{NDVI}_{\max }-\mathrm{NDVI}_{0}}
$$

$\mathrm{NDVI}_{0}$ is the value corresponding to bare soil and $\mathrm{NDVI}_{\max }$ is the value corresponding to the full vegetation [15].

\subsubsection{Derivation of Emissivity Corrected Surface Radiant Temperature}

The surface emissivity can be incorporated into thermal atmospheric correction of thermal remotely sensed data so as to determine accurate radiometric temperatures [15]. Therefore, surface emissivity was computed so as to incorporate it into land surface temperature derivation algorithm.

$$
T=\frac{K_{2}}{\ln \left(\frac{K_{1} * \varepsilon}{C V_{R 1}}+1\right)}
$$

where: $T$ is in degrees Kelvin. It can be converted to degree Celsius by subtracting 273.15 from the Kelvin values.

$K_{1}$ and $K_{2}$ are calibration constants for Landsat $7 \mathrm{ETM}+$ equal to $666.09 \mathrm{~W} \mathrm{~m}^{-2} \mathrm{sr}^{-1} \mu \mathrm{m}^{-1}$ and $1282.71 \mathrm{~W} \mathrm{~m}^{-2}$ $\mathrm{sr}^{-1} \mu \mathrm{m}^{-1}$ respectively [13] [16]. (8).

$\mathrm{CV}_{\mathrm{RI}}$ is cell value as radiance ( $\mathrm{W} \mathrm{m} \mathrm{m}^{-2} \mathrm{sr}^{-1} \mu \mathrm{m}^{-1}$ ); $\varepsilon$ is surface emissivity [unitless] computed using Equation

$$
\varepsilon_{i}=F r \cdot \varepsilon_{v}+(1-F r) \cdot \varepsilon_{s}
$$

where: $F r$ is fractional vegetation cover; $\varepsilon_{i}$ is pixel's emissivity; $\varepsilon_{v}$ is emissivity of vegetation; $\varepsilon_{s}$ is emissivity of soil.

\subsubsection{Scaling NDVI and Surface Radiant Temperature}

The NDVI was scaled using the formula discussed above in Equation (6). Surface radiant temperature was also scaled likewise according to [6] algorithm.

$$
T^{*}=\left\{\frac{\left(T_{i r}-T_{\min }\right)}{\left(T_{\max }-T_{\min }\right)}\right\}
$$

where: $T_{\text {ir }}$ is surface radiant temperature; $T_{\min }$ is minimum temperature in the image; $T_{\max }$ is maximum temperature in the image. Both the $N^{*}$ and $T^{*}$ values range from 0 to 1 .

\subsubsection{Creation of $T^{*}$-Fr Triangular Space}

A scatter plot of $F r$ versus scaled surface radiant temperature was developed for each date in order to observe the triangle. The Fr was plotted on ordinate while the scaled surface radiant temperature on abscissa. An algorithm was used to fit the warm edge according to [2] procedure.

$$
T_{\max (i)}^{*}=a+b F r_{i}
$$

where: $F r_{i}$ is the fractional vegetation cover of pixel $i$-th pixel; $a$ is the intercept of the linear warm edge; $b$ is the slope of the linear warm edge. 


\subsubsection{Transformation of Pixel Measurements into Soil Surface Wetness}

Pixel measurements were transformed into soil surface wetness (moisture availability) using 3rd order polynomial equation developed by [6] from the output of Soil Vegetation Atmosphere Transfer Model (SVAT). The inputs of this polynomial algorithm are fractional vegetation cover, scaled surface radiant temperature and coefficients.

$$
\left(M_{o}\right)=\sum_{i=0}^{3} \sum_{j=0}^{3} a_{i j} T^{* i} F^{j}
$$

where: $M_{o}$ is moisture availability (soil surface wetness) at a pixel; $T^{*}$ is pixel's scaled surface radiant temperature; $F r$ is pixel's fractional vegetation cover; $a_{i j}$ is coefficient of the equation.

\section{Results and Discussion}

\section{1. $T^{*}$-Fr Scatter Plot}

The scatter plot of the $T^{*}$ versus Fr resembles a triangle in each date under study (Figure 2). Fr was plotted on the ordinate while the scaled surface radiant temperature on the abscissa. The emergence of the triangular space

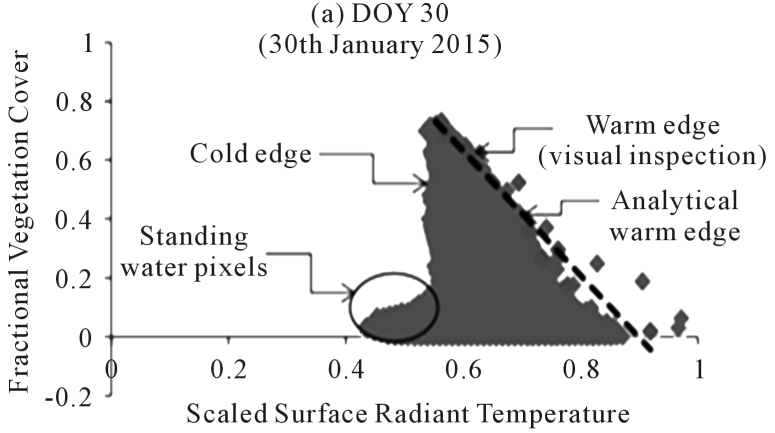

(c) DOY 78

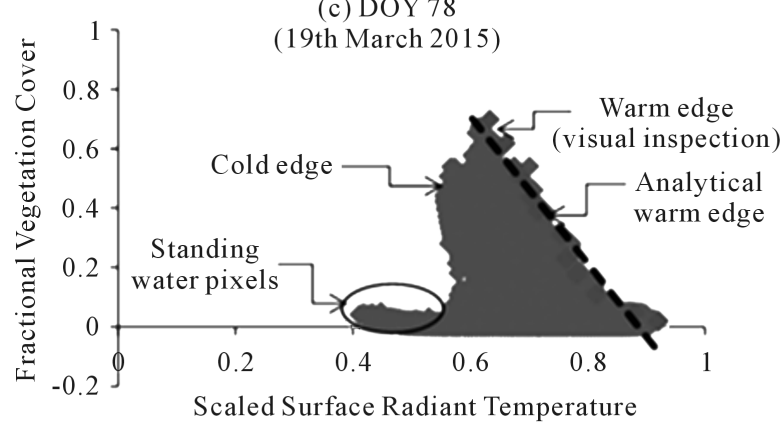

(b) DOY 46

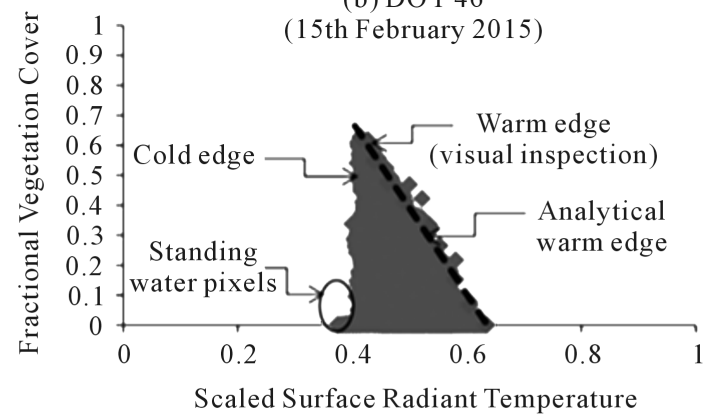

(d) DOY 110

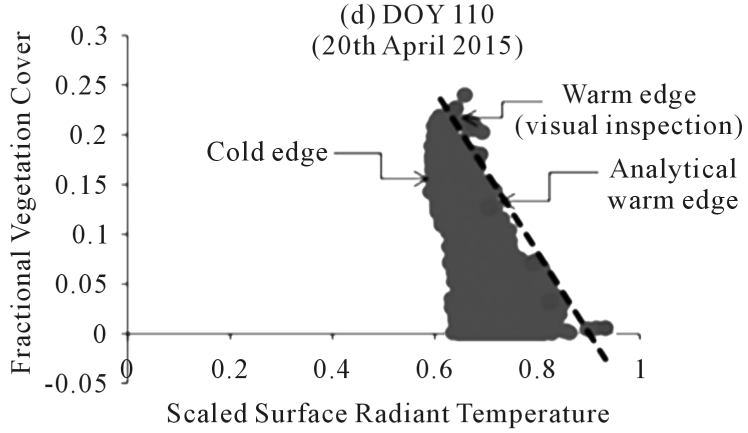

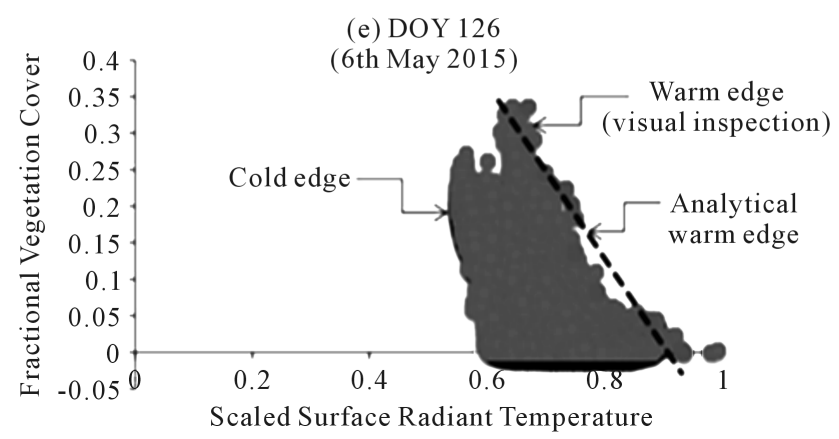

Figure 2. Triangular space of scaled surface radiant temperature versus fractional vegetation cover (before removal of standing water pixels). 
is an indication of the presence of wide range of soil surface wetness within the area under investigation. These findings are in accord with the interpretation of triangular space by [6] [17] [18].

The moisture availability (soil surface wetness) varies linearly from the warm edge (Mo equals to zero) to the cold edge (Mo equals to 1 ). The warm edge is the right edge of the distribution and it represents the pixels with warm surface temperature. The higher surface radiant temperature along this edge is either as a result of low evaporation rates from dry soils under low vegetation condition or low transpiration rates from vegetation canopy under high ground vegetation cover (owing to the low soil moisture) which in turn causes stomatal closure in the canopy. The left edge is defined as the cold edge. Pixels along this edge have cool surface temperature. This is because of high evaporation rates from wet soils under low vegetation condition or high transpiration from vegetation canopy under high vegetation condition which indicates the presence of high amount of moisture and lack of water stress.

The cloud and water pixels distort the shape of the triangle around the boundaries. It is very noticeable in the triangles of the 30th January, 2015 (DOY 30), 15th February, 2015 (DOY46) and 19th March, 2015 (DOY 78) that the triangles bulge in the lower left side. This distortion is likely to be caused by standing water pixels because of lower reflectivity and a bit higher temperature of water in comparison with cloud. Figure 3 depicts the results of standing water pixels' distortions removal on 30th January, 2015, 15th February, 2015, and 19th March, 2015).

(a) DOY 30

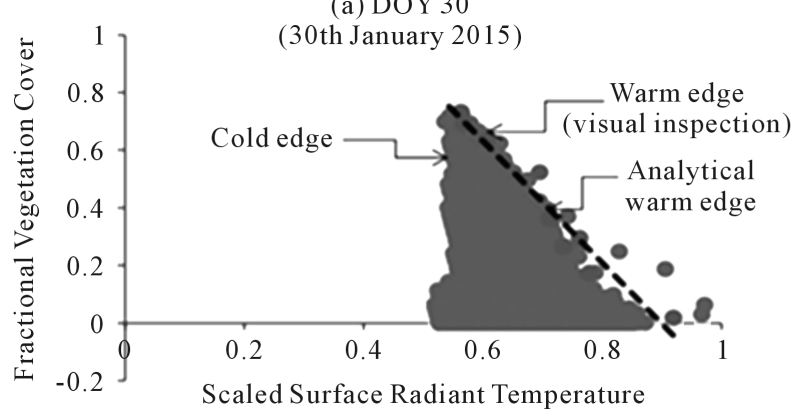

(c) DOY 78

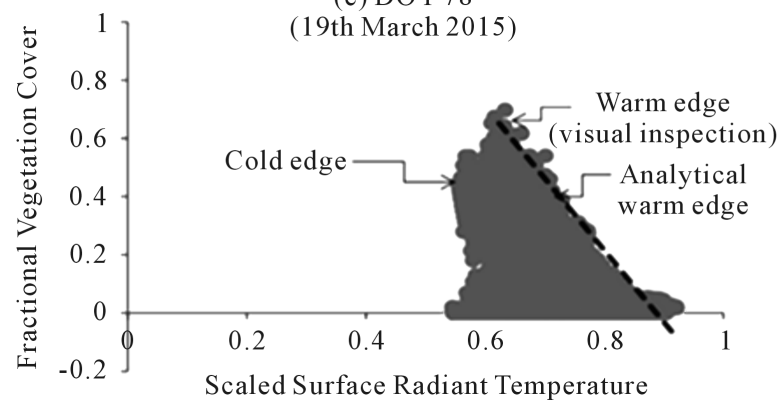

(b) DOY 46

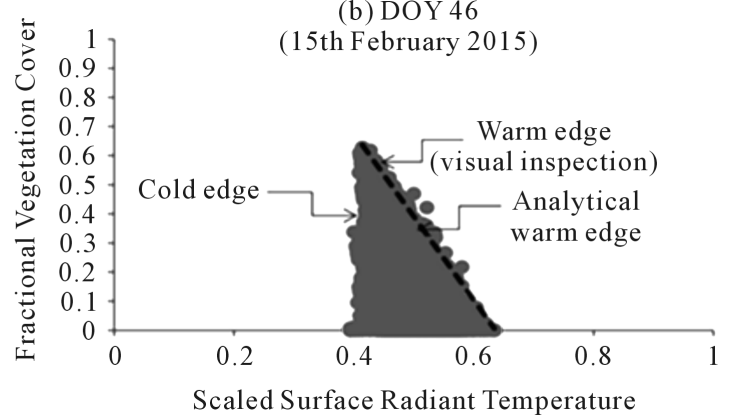

(d) DOY 110

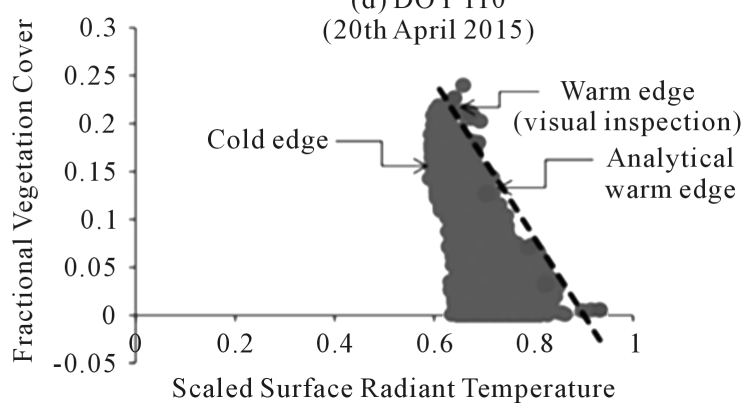

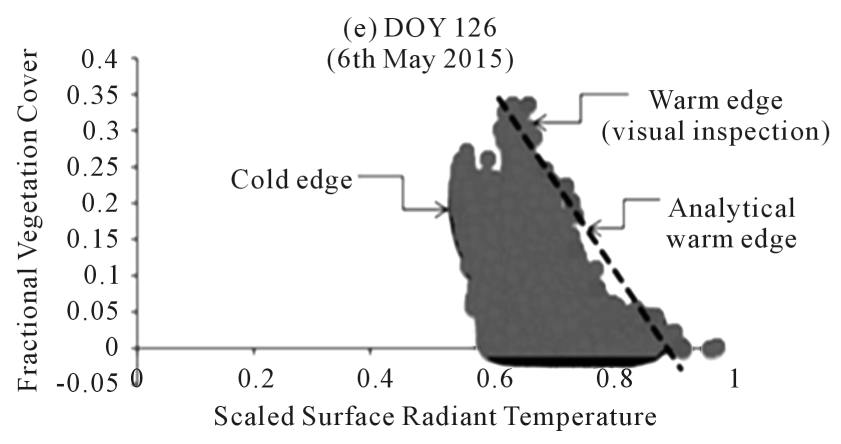

Figure 3. Triangular space of scaled surface radiant temperature versus fractional vegetation cover (After removal of standing water pixels). 


\subsection{Spatial and Temporal Distribution of Soil Surface Wetness}

Soil surface wetness tends to vary spatially and temporally owing to the certain factors such as the nature of the scenery, soil type, land use et cetera. Chaka block in Allahabad was chosen to show the spatial variation of simulated soil surface wetness. The findings have shown that soil surface wetness varied spatially and temporally within the area under investigation. Figure 4 depicts the spatial variability maps of simulated soil surface wetness
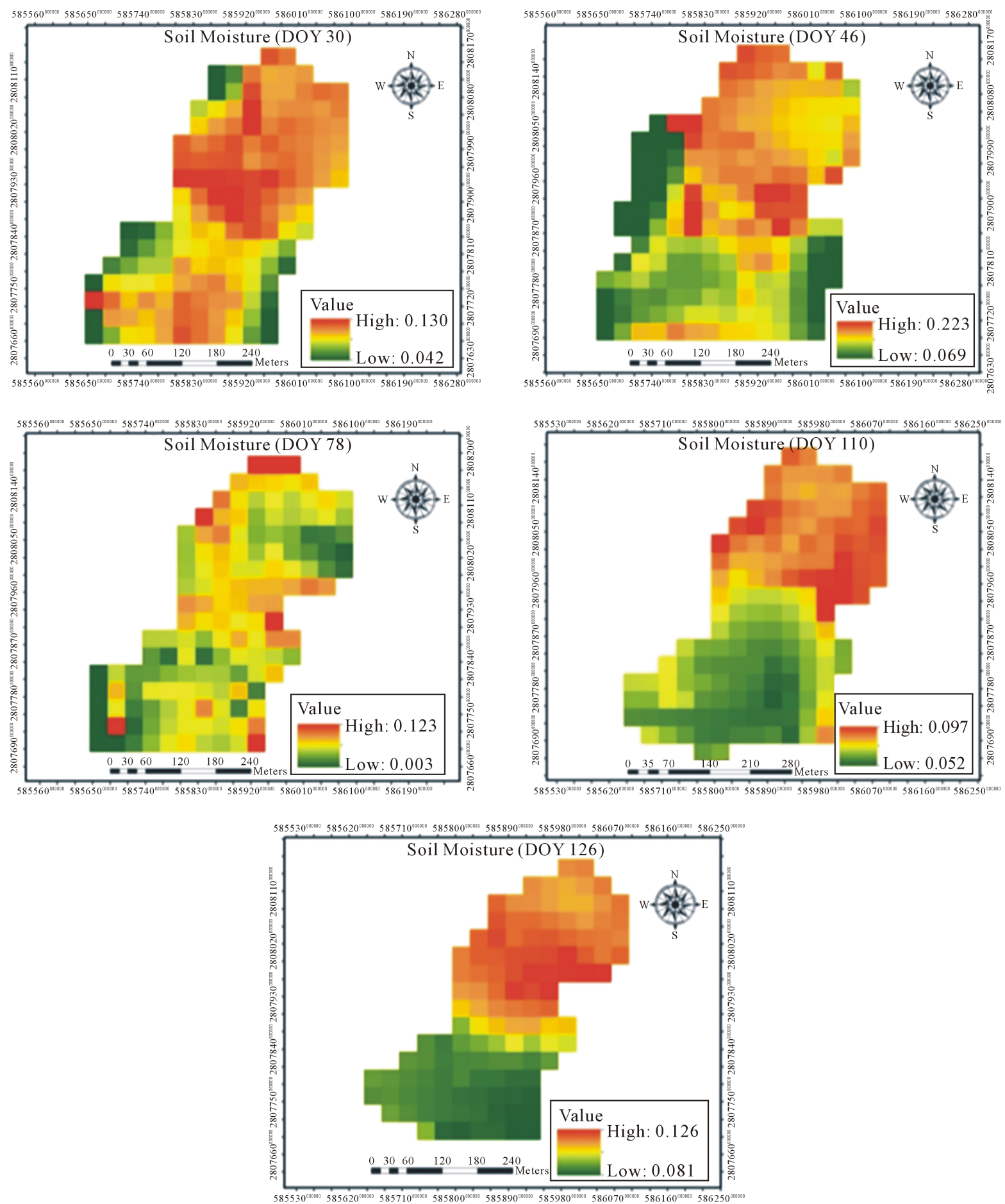

Figure 4. Spatial distribution of simulated soil surface wetness in Chaka block. 
Table 1. Correlation coefficient $\left(R^{2}\right)$ between simulated soil surface wetness and ground measured volumetric water in Chaka block.

\begin{tabular}{cccc}
\hline \multirow{2}{*}{ S. No. } & Date & \multicolumn{2}{c}{ 3rd Order Polynomial Algorithm } \\
\cline { 3 - 4 } & & SM (5 cm) & SM $(15 \mathrm{~cm})$ \\
\hline 1 & 30th Jan, 15 & 0.0175 & 0.0088 \\
2 & 15th Feb, 15 & 0.0403 & 0.0114 \\
3 & 19th Mar, 15 & 0.0111 & 0.0674 \\
4 & 20th Apr, 15 & 0.0493 & 0.0827 \\
5 & 6th May, 15 & 0.1152 & 0.1380 \\
\hline
\end{tabular}

at $30 \mathrm{~m}$ resolution using third order polynomial algorithm on the study dates. The range of soil surface wetness decreases progressively between DOY 46 and DOY 110. This might be as a result of the absolute cessation of rainfall between March and April.

\subsection{Correlation Analysis}

The simulated soil surface wetness using the 3rd order polynomial algorithm was correlated with ground measured volumetric soil moisture at depths $0-5 \mathrm{~cm}$ and $15 \mathrm{~cm}$. The findings showed a very weak correlation between the simulated soil surface wetness and ground measured soil moisture at deeper soil layers (Table 1 ). This indicated that triangle method can only estimate soil surface wetness at superficial layer of the soil $(0.5$ to $1 \mathrm{~cm})$. This should be taken into consideration when the method is being applied.

The weak correlation between the simulated and measured soil moisture (soil surface wetness) can be attributed to the depth at which soil moisture measurements were made. To find out the possible reason(s) for the weak correlation between simulated and estimated soil moisture in the present study, series of personal communications were made with the developer of the algorithm [19] in May, 2015 (Professor Toby N. Carlson, Penn State University, USA). According to [19] it might be difficult to get a good correlation between ground measured volumetric soil surface moisture at deeper substrate and estimated soil surface wetness using triangle method, as the latter technique estimates moisture availability (soil surface wetness) at the top skin layer of the soil $(0.5$ to $1 \mathrm{~cm})$. This is because the drying rates at the surface discontinue to be linearly correlated to that at lower levels (depths) during the satellite overpass.

\section{Conclusion}

This study demonstrated the efficient remote sensing techniques for estimating soil surface wetness (surface moisture availability) using a relationship between scaled surface radiant temperature and fractional vegetation cover on the triangular space (triangle method). The simulated soil surface wetness and ground measured soil moisture did not correlate well. The possible reason of poor correlation between simulated and measured soil moisture could be attributed to the depth at which soil moisture measurements were made. In this regard, triangle method had capability of estimating soil moisture at the superficial soil layer $(0.5-1 \mathrm{~cm})$.

\section{Acknowledgements}

The authors would like to express their gratitude to Professor Emeritus Toby Nahum Carlson of Penn State University, USA for his precious advice and help.

\section{References}

[1] Su, Z. (2009) Microwave Remote Sensing of Soil Moisture. The Netherlands: International Institute for Geo-Information Science and Earth, Enschede.

[2] Mallick, K., Bhattacharya, B.K. and Patel, N. (2009) Estimating Volumetric Surface Moisture Content for Cropped Soils Using a Soil Wetness Index Based on Surface Temperature and NDVI. Agricultural and Forest Meteorology, 149, 1327-1342. http://dx.doi.org/10.1016/j.agrformet.2009.03.004 
[3] Haas, J. (2010) Soil Moisture Modelling Using TWI and Satellite Imagery in the Stockholm Region. Royal Institute of Technology (KTH), School of Architecture and the Built Environment. Stockholm, Sweden.

[4] Carlson, T.N., Dodd, J.K., Benjamin, S.G. a nd Cooper, J.N. (1981) Satellite Estimation of the Surface Energy Balance, Moisture Availability and Thermal Inertia. Journal of Applied Meteorology, 20, 67-87. http://dx.doi.org/10.1175/1520-0450(1981)020<0067:SEOTSE>2.0.CO;2

[5] Mekonnen, D.F. (2009) Satellite Remote Sensing for Soil Moisture Estimation: Gumara Catchment, Ethiopia. International Institute for Geo-information Science and Earth Observation, Enschede.

[6] Carlson, T.N. (2007) An Overview of the "Triangle Method" for Estimating Surface Evapotranspiration and Soil Moisture from Satellite Imagery. Sensors, 7, 1612-1629. http://dx.doi.org/10.3390/s7081612

[7] Bryant, R., Thoma, D., Moran, S., Holifield, C., Goodrich, D., Keefer, T., et al. (2003) Evaluation of Hyperspectral, Infrared Temperature and Radar Measurements for Monitoring Surface Soil Moisture. Proceedings of the 1st Interagency Conference on Research in the Watersheds. USDAARS, Beltsville, 528-533.

[8] Allahabad Profile (2015) http://allahabad.nic.in/geostructure.htm

[9] Allahabad Wikipedia (2015) https://en.wikipedia.org/wiki/Allahabad

[10] National Disaster Risk Reduction Portal (2015) http://nidm.gov.in/pdf/dp/Uttar.pdf

[11] Methods Manual, Soil Testing in India (2011) New Delhi, India: Department of Agriculture \& Cooperation Ministry of Agriculture Government of India.

[12] Uttar Pradesh District Profile (2015) http://zpdk.org.in/sites/default/files/districtprofile(2-2-10).pdf

[13] Chander, G., Markham, B.L. and Helder, D.L. (2009) Summary of Current Radiometric Calibration Coefficients for Landsat MSS, TM, ETM+, and EO-1 ALI Sensors. Remote Sensing of Environment, 113, 893-903. http://dx.doi.org/10.1061/(ASCE)1084-0699(2008)13:2(51)

[14] Tasumi, M., Allen, R.G. and Trezza, A.R. (2008) At-Surface Reflectance and Albedo from Satellite for Operational Calculation of Land Surface Energy Balance. Journal of Hydrologic Engineering, 13, 2. http://dx.doi.org/10.1061/(ASCE)1084-0699(2008)13:2(51)

[15] Brunsell, N.A. and Gillies, R.R. (2002) Incorporating Surface Emissivity into a Thermal Atmospheric Correction. Photogrammetric Engineering \& Remote Sensing, 68, 1263-1269.

[16] Mallast, U., Gloaguen, R., Friesen, J., Rödiger, T., Geyer, S., Merz, R., et al. (2014) How to Identify Groundwater-Caused Thermal Anomalies in Lakes Based on Multi-Temporal Satellite Data in Semi-Arid Regions. Hydrology and Earth System Sciences, 18, 2773-2787. http://dx.doi.org/10.5194/hess-18-2773-2014

[17] Yang, X., Wu, J.J., Shi, P.J. and Yan, F. (2008) Modified Triangle Method to Estimate Soil Moisture Status with Moderate Resolution Imaging Spectroradiometer (MODIS) Products. The International Archives of the Photogrammetry, Remote Sensing and Spatial Information Sciences, Vol. XXXVII. Part B8, Beijin, 2008, 555-560.

[18] Chen, C.-F., Son, N.-T., Chang, L.-Y. a nd Chen, C.-C. (2011) Monitoring of Soil Moisture Variability in Relation to Rice Cropping Systems in the Vietnamese Mekong Delta Using MODIS Data. Applied Geography, 31, 463-475. http://dx.doi.org/10.1016/j.apgeog.2010.10.002

[19] Carlson, T.N. (2015) Personal Communication by Email. (Abba Aliyu Kasim, Interviewer) 